eosin is less widely used but ensures better cellular detail and enables counts similar to those of vaginal cytology to be made. ${ }^{18}$ Before 32 weeks basal cells predominate, whereas sheets of anucleate squames are characteristic of term.

Of the physiochemical characteristics of the amniotic fluid the most reliable appear to be the concentrations of creatinine and urea. They rise steadily after 30 weeks and reflect increasing fetal renal function, ${ }^{19}{ }^{20}$ as does osmolarity, ${ }^{21}$ which falls during this period. Thus, if the creatinine concentration is greater than $1.6 \mathrm{mg}$. per $100 \mathrm{ml}$. the pregnancy is almost certainly more advanced than 38 weeks and the fetal weight more than 2,500 g. ${ }^{22}$ The converse is not true, and a post-term pregnancy is not associated with a continued rise. The absence of the peak of optical density at $450 \mu$ reflects increasing ability of the fetal liver to conjugate bilirubin and indicates a pregnancy in excess of 36 weeks. ${ }^{23}$ Other less widely used methods are vaginal cytology ${ }^{24}$ and cell counts in amniotic fluid. ${ }^{16}$

It is apparent that all special investigations of menstrual age are subject to error in the very cases where the information is most necessary-intrauterine malnutrition and postmaturity. They can therefore be regarded only as confirmatory to clinical impression when a positive result is obtained. It is still debatable whether routine induction of labour reduces the overall risk to the fetus in a post-term gestation. ${ }^{25} 26$ Functional maturity and fetal well-being are more important than chronological age. ${ }^{25} 27$

\section{Deaf Children}

Education of the deaf child has been a controversial problem since the divergent solutions developed by the Abbé de l'Epée in France and Pastor Samuel Heinicke in Germany during the eighteenth century. They were the forerunners of what are now termed the manual and oral methods, both relying on earlier work.

Manual methods encourage the use of hand gestures to convey meaning by using different positions of the hands and fingers to represent either objects and activities, as in making signs, or the individual letters of the alphabet, as in fingerspelling. Sir Richard Paget ${ }^{1}$ recognized the haphazard and ungrammatical nature of making signs ("signing") and developed a systematic sign language which forestalls much of the criticism previously levelled at such methods. Oral methods rely on perception of the spoken word and the conveying of language by speech. I. R. and A. W. G. Ewing ${ }^{2}$ at Manchester have been the leaders of this approach in Britain. In its most rigorous form teachers have forbidden the use of any form of gesture and lip-reading. On the medical side E. Whetnall ${ }^{3}$ rightly stressed the need for early diagnosis.

Present practice in Britain has been towards the early detection of hearing loss, the fitting of a hearing aid, and pre-

\footnotetext{
' Paget, R., Gorman, P., and Paget, G., A Systematic Sign Language, 4th

${ }^{2}$ Edn. London, the authors, 1969. Manchester University Press, 1954.

3 Whetnall, E., Fournal of Laryngology and Otology, 1956, 70, 630.

3 Whetnall, E., Fournal of Laryngology and Otology,
4 Hine, W. D., Teacher of the Deaf, 1970, 68, 129.

4 Hine, W. D., Teacher of the Deaf, 1970, 68, 129.
s Department of Education and Science, The Education of Deaf Children Department of Education and Science, The Education of Deaf Children;
The Possible Place of Finger-Spelling and Signing. London, H.M.S.O.,

" Conrad, R., Profound Deafness as a Psycholinguistic Problem. Paper presented at Symposium on Speech Communication Ability and Profound Deafness. August 12-14, 1970. Stockholm.
}

school auditory training. It is based on the premise that virtually no child is so profoundly deaf that he has no usable residual hearing. There are some remarkable success stories, and children with $80-90 \mathrm{~dB}$ hearing losses have succeeded in ordinary school, but they are the exception. Even children with less severe deafness, the partially hearing, fall well behind the accomplishments of their normally hearing brothers and sisters. Studies such as W. D. Hine's ${ }^{4}$ indicate a four-year deficit in reading skill by the age of 16 and up to three years in mathematics.

Growing concern with the results of educational practice in this country, particularly in comparison with those reported from Russia and the U.S.A., prompted the Department of Education to set up a committee of inquiry under Professor M. M. Lewis. Its report ${ }^{5}$ considered the value of making signs and of finger-spelling and is essentially an attempt to adjudicate between the two main schools. It performed a valuable service in bringing to a wider public the work of other countries, such as the introduction of finger spelling to preschool children in Russia and the combined hand-mouth system used in Denmark. In the U.S.A. the situation is rather different in that there are two separate traditions, one based on purely oral methods, the other on a combined oral and manual approach, though even here the oral method alone is commonly used in preschool and early school years.

The long-standing polarization between oral and manual methods has clouded the issue for too long. There is undue emphasis on output and on the vocabulary size of the child with a hearing loss and too little consideration of the importance of understanding. Even less consideration has been given to the role of language in the organization of thought, and a deaf child's cognitive abilities are rarely developed to their full potential. Teaching methods, oral or manual, have been derived from an adult understanding of the severe language deprivation of the child. There has been no thought for the qualitative difference between hearing and nothearing. Man acquired spoken language through many generations by a process of learning that necessitated a progressive fusion between what was heard and what was uttered. How far is this process appropriate for a child with little hearing and gross limitation of speech? R. Conrad's ${ }^{6}$ work on memory and recall suggests that the deaf frequently use a different mental imagery from the auditory-articulatory process used by normally hearing speakers. This poses the question, If we try to make the deaf speak like the hearing, are we trying to make them think like the hearing? And we must bear in mind that thought processes mediated by the spoken word are not available to them.

There has been some change in the management of individual children since Amman wrote Surdus Loquens in 1692. But the problems continue to overshadow the solutions so far proposed. Greater skill in medical assessment is needed. The full extent of the perceptual disorder rather than simply the level of threshold hearing levels needs to be studied, as does any impairment there may be of visual and other sensation, and any effect on motor function, particularly in the speech apparatus, as well as on other aspects of the central nervous system. The increasingly powerful resources of experimental and educational psychology should be combined with medicine and developmental linguistics to guide the teacher into new forms of management. 